SAND--91-2214C

DE92 000978

SAND91-2214C

\title{
A SUMMARY OF HIGH-TEMPERATURE ELECTRONICS RESEARCH AND DEVELOPMENT
}

Frank V. Thome

Sandia National Laboratories

P. O. Box 5800

Division 6474

Albuquerque, NM 87185-5800

(505) 272-7218 / (505) 845-7845
Donald B. King

Sandia National Laboratories

P. O. Box 5800

Division 6474

Albuquerque, NM 87185-5800

(505) 845-7842

\section{DISCLAIMER}

This report was prepared as an account of work sponsored by an agency of the United States Government. Neither the United States Government nor any agency thereof, nor any of their employees, makes any warranty, express or implied, or assumes any legal liability or responsibility for the accuracy, completeness, or usefulness of any information, apparatus, product, or process disclosed, or represents that its use would not infringe privately owned rights. Reference herein to any specific commercial product, process, or service by trade name, trademark, manufacturer, or otherwise does not necessarily constitute or imply its endorsement, recommendation, or favoring by the United States Government or any agency thereof. The views and opinions of authors expressed herein do not necessarily state or reflect those of the United States Government or any agency thereof. 


\section{A SUMMARY OF HIGH-TEMPERATURE ELECTRONICS RESEARCH AND DEVELOPMENT}

Frank V. Thome

Sandia National Laboratories

P. O. Box 5800

Division 6474

Albuquerque, NM 87185-5800

(505) 272-7218 / (505) 845-7845
Donald B. King

Sandia National Laboratories

P. O. Box 5800

Division 6474

Albuquerque, NM 87185-5800

(505) 845-7842

CAMERA READY MANUSCRIPT prepared for:

Ninth Symposium

on Space Nuclear Power Systems

Albuquerque, New Mexico

12-16 January 1992

final submission: 18 October 1991

Author to whom correspondence should be sent: Donald B. King 


\title{
A SUMMARY OF HIGH-TEMPERATURE ELECTRONICS RESEARCH AND DEVELOPMENT
}

\author{
Frank V. Thome \\ Sandia National Laboratories \\ P. O. Box 5800 \\ Division 6474 \\ Albuquerque, NM 87185-5800 \\ (505) 272-7218 / (505) 845-7845
}

\author{
Donald B. King \\ Sandia National Laboratories \\ P. O. Box 5800 \\ Division 6474 \\ Albuquerque, NM 87185-5800 \\ (505) 845-7842
}

\begin{abstract}
$\underline{\text { Abstract }}$
Current and future needs in automotive, aircraft, space, military, and well logging industries require operation of electronics at higher temperatures than today's accepted limit of $395 \mathrm{~K}$. Without the availability of high-temperature electronics, many systems must operate under derated conditions or must accept severe mass penalties required by coolant systems to maintain electronic temperatures below critical levels. This paper presents ongoing research and development in the electronics community to bring high-temperature electronics to commercial realization. Much of this work was recently reviewed at the First International High-Temperature Electronics Conference held 16-20 June 1991 in Albuquerque, New Mexico.

\section{INTRODUCTION}

An interest in high-temperature solid-state electronics has existed since the introduction of semiconductors during the 1950 s. Current electronic technology operates to the MIL-SPEC limits of $395 \mathrm{~K}$ to $423 \mathrm{~K}$. Operation above $420 \mathrm{~K}$ causes reducticn in semiconductor performance, lifetime, and reliability. The Air Force at Wright Laboratory has been investigating the potential for high-temperature electronics development to satisfy future high temperature advanced aircraft and space power needs. In support of Wright Laboratory, Sandia National Laboratories has conducted two workshops (Thome and King 1989 and Thome, King, and Severt 1991-A) and one international conference (King, Thome., Severt 1991-B,C) to identify the technical issues and recommend research to satisfy high temperature needs for electronics. All electronic parts were investigated (capacitors, resistors, magnetics, and semiconductors), but most of our work addressed high-temperature semiconductors. Our semiconductor survey included research in silicon, gallium arsenide, other III - V compounds, silicon carbide, and diamond. We also reviewed Thermionic Integrated Circuits (TICs) and Field Emitter Arrays (FEAs) for integrated circuits and power applications. The June 1991 First International High-Temperature Electronics Conference had 145 participants, representing 34 private companies, 12 government laboratories, and 12 universities. There were 57 technical presentations on the electronic components discussed above with data presented for temperatures as high as $920 \mathrm{~K}$. The conmunities with the greatest need for high-temperature electronics are the geothermal and oil well logging industries, the automotive industry, the military (aircraft and ground power conditioning), and the space power and space exploration scientific communities.
\end{abstract}

\section{USERS AND NEEDS}

A summary of the status of the needs by community and the progress needed to satisfy their needs will be presented below.

\section{WELL LOGGING}

More than 40,000 wells are being logged per year by the oil industry. While temperature requirements are generally less than $445 \mathrm{~K}$ (495 $\mathrm{K}$ for gas wells), the temperature can range up to $585 \mathrm{~K}$ for several hours during logging. Enhanced oil recovery by steam injection will expose logging electronics to temperatures ranging from 
$470 \mathrm{~K}$ to $570 \mathrm{~K}$ for long periods of time. Schlumberger conducts over $\$ 5$ billion per year of business in its drilling and well logging activities. The electronic and electrical parts needed range from cabling, connectors, and passive devices (capacitors and transformers) to A/D conventers, EPROMs, operational amplifiers, batteries, motors, and solenoids.

Geothermal well logging occurs at a rate of about 800 wells per year. Operational temperatures are generally worse than those for oil well logging and can range to $670 \mathrm{~K}$ for wells being drilled to depths greater than $11 \mathrm{~km}$. The success of both the oil and geothermal industries for energy production will depend on the ability to make accurate in situ measurements over a long period of time. Sandia and Los Alamos National Laboratories in New Mexico and UNICAL in California have played major roles in geothermal energy production.

\section{AUTOMOTIVE INDUSTRY}

The temperature needs of the automotive industry can range from $410 \mathrm{~K}$ to $970 \mathrm{~K}$. Present needs require sensors that can survive $970 \mathrm{~K}$ to analyze exhaust gas constituents and temperature. The exhaust gas sensor represents an extreme temperature requirement. More typical temperature requirements range from $410 \mathrm{~K}$ to $570 \mathrm{~K}$. This lower temperature range for electronics would include engine block embedded sensors to monitor cylinder pressure and temperature, sensors in brake pads, transmissions, and in chemical fluid reservoirs to evaluate oil, coolant, and fuel consumption. Future plans include electronically controlled torque-demand engines, transmissions, four-wheel drive traction controls, anti-lock brakes, and under-the-hood diagnostic microprocessors. At present, a large number of hybrid circuit failures occur in certain car models with under-the-hood temperatures at $410 \mathrm{~K}$. As automobile aerodynamics improve, air flow through the engine compartment will decrease and the under-the-hood temperatures will continue to rise dramatically. In all cases evaluated to date by the automotive industry, electronic packaging is the most limiting aspect of electronics parts. The automobile manufacturers are beginning to invest more money per car to develop high-temperature electronics for reliable operation. Electronic parts (without entertainment systems) account for $\$ 1,000$ per car, and 107 cars are produced per year.

\section{AIRCRAFT INDUSTRY}

The aircraft industry has recognized since the mid 1960 s, that placing monitor and control electronics directly on the jet engines (a distributed system) could provide many benefits, especially in military aircraft. Electronics capable of operating at $570 \mathrm{~K}$ will satisfy most engine monitoring and control needs. Present aircraft configurations place the monitor and control electronics in a centrally located service bay. Damage to the service bay results in loss of aircraft control. A distributed system would diminish failure of the control electronics by requiring many locations on the aircraft to be damaged. Control electronics located in the service bay also increases installation problems by requiring a large number of wire interconnects from aircraft control points to the service bay. The distributed system would reduce the number of wire interconnects required. High-temperature electronics would also eliminate today's practice of cooling electronics with jet fuel; mass would be saved by eliminating coolant pipes, pumps, and special electronic housings to accept fuel coolant. Presently, $40 \%$ of all monitoring and control failure problems are electronic. Using high-temperature electronics should increase the reliability of these parts. Another aspect of high performance aircraft is the effect of Mach speeds on control surface and engine inlet temperatures. Studies and research have shown that leading edge temperatures can range from $810 \mathrm{~K}$ to $920 \mathrm{~K}$ at Mach 5 depending on the surface location of the aircraft. Without the availability of high-temperature electronics, electronic sensors and counter measures (ECM) equipment positioned at the surfaces would require complex cooling systems.

The availability of high-temperature electronics can also have dramatic effects on power generation and distribution onboard aircraft. The E-4B (a 747 modified as an airborne command post) can generate a maximum of $1.2 \mathrm{MW}$ for onboard loads. The actual power load is limited to $700 \mathrm{~kW}$ at high elevation operation because ejection of electronic waste heat decreases at high altitudes and temperatures would exceed safe electronic operating ranges. A large fraction of the power load is dedicated to fans and air conditioning to cool the onboard electronics. The F$15 \mathrm{~A}$ fighter has a power requirement of $55 \mathrm{~kW}$, and the F-15E has a power requirement of $152 \mathrm{~kW}$. All of the power load increase is due to enhanced avionics and its associated cooling requirements. Future military aircraft 
(Year 2005) are planned to be controlled by electrical actuators (hydraulic free control). The electrical actuators will require high power electrical devices capable of high-temperature operation. Many of these devices will need to be positioned in the aircraft without access to cooling.

All equipment onboard aircraft have a mass penalty. For commencial aircraft, each excess pound costs the aircraft industry $\$ 10,000$ over a 15 year life (based on a fleet of 300 aircraft). The excess mass is due to the need for air conditioners, fans, large generators, and switch gear. High-temperature electronics is the obvious solution to reduce mass associated with the need to cool electronics.

\section{SPACE REQUIREMENTS}

The SP-100 and Multimegawat (MMW) reactor space power programs have introduced the reactor and electronic communities to the problem of having to dissipate all of the generated electrical power (100s of $\mathrm{kWe}$ to $\mathrm{MWe}$ ). Most of the energy ends up in the form of heat from electrical and electronic components in the payload. If the payload bay must be maintained at low temperatures ( $395 \mathrm{~K}$ to $420 \mathrm{~K}$ for today's state-of-the-art electronics), then the mass and volume of the necessary space "payload" radiator become the single largest fraction on the space platform. The problem also exists for smaller power plants because of the desire to make the overall systems small, forcing the electrical payloads to be in close proximity to the power plant heat sources. Another aspect relevant to nuclear power plants of all sizes is the need for instrumentation and control electronics to be close to the reactor. This requirement is dictated by the need to boost the signal-to-noise ratio of low-level signals and to provide multiplexers that reduce the number of wires that are used for signals and control. The best location for these devices and circuits is next to the reactor shield. For SP-100, these temperatures are around $645 \mathrm{~K}$ to $695 \mathrm{~K}$ and the total gamma dose is about $120 \mathrm{Mrad}(\mathrm{Si})$ at a dose rate of about $1.5 \mathrm{krad} / \mathrm{h}$, while the total neutrons are about $1.6 \times 10^{15} \mathrm{nvt}$. These requirements are by far the most severe found anywhere in the industry including the nuclear weapons community. The requirements are even more severe for MMW.

Scientific space missions to other planets and deep space introduce other requirements. The lack of $720 \mathrm{~K}$ electronic devices prevented an adequately instrumented Venus surface probe mission in conjunction with the USSR. We ended up targeting an atmospheric mission only, without a landing, using $420 \mathrm{~K}$ parts. The data transmission ended after 45 hours.

\section{APPLICABLE SEMICONDUCTOR TECHNOLOGIES}

Semiconductor materials most commonly being studied for high-temperature applications include silicon, gallium arsenide (GaAs), aluminum gallium arsenide ( $\mathrm{AlGaAs}$ ), silicon carbide ( $\mathrm{SiC}$ ), and diamond. The silicon and $\mathrm{GaAs}$ materials have been fabricated into discrete devices, as well as integrated circuits for high-temperature applications. The SiC and diamond materials do not have the technological maturity that silicon has; studies are still ongoing to understand material growth issues. Therefore, high-temperature studies for $\mathrm{SiC}$ and diamond are still limited to material and simple discrete device performance.

\section{SILICON}

Commercially available silicon devices designed for MIL-SPEC limits of $395 \mathrm{~K}$ to $420 \mathrm{~K}$ are capable of operating at much higher temperatures depending on whether the devices are discrete or part of integrated circuits. The temperature limitation can be due to the silicon material itself, the method and feature sizes of the device process, the circuit design, or the packaging of the device.

Discrete silicon devices have demonstrated adequate short-term performance for temperatures ranging from $470 \mathrm{~K}$ to $570 \mathrm{~K}$. In general, for small devices, leakage currents in the devices do not increase above useable levels. Doping concentrations can be increased somewhat to delay the intrinsic threshold. Unfortunately, these hightemperature tests last only a few days at best, and reliability of the device metallization, interconnects, and packaging for long-term operation is uncertain. Conventional aluminum and gold metals are not acceptable, especially without 
barriers. Barrier materials such as CVD tungsten show great promise to at least $570 \mathrm{~K}$. Long-term test data is needed to determine acceptable packaging techniques at high temperatures.

Bulk silicon integrated circuits have shown acceptable performance up to $445 \mathrm{~K}$. Performance deteriorates due to elevated leakage currents and latchup. Epitaxial silicon integrated circuits have increased acceptable performance temperatures to $420 \mathrm{~K}$ due to much improved latchup immunity. SOI silicon integrated circuits have the best temperature performance and can currently reach tem aures of $620 \mathrm{~K}$. This enhanced high-temperature performance is due to small junction sizes which reduce leakage currents and the insulator material which eliminates latchup.

Besides process modifications (bulk, epi, SOI, modifying doping levels), other strategies to enhance hightemperature performance include changing layout rules and circuit designs. One layout rule currently in use is channel length scaling in MOSFE is to minimize mobility degradation and maintain circuit speed. As temperature increases and mobility decreases, the channel length is appropriately decreased to maintain circuit speed. Circuit designs can overcome some of the poor performance characteristics at elevated temperatures. For example, zero temperature coefficient optimization provides the best biasing points and minimizes device parameter change with temperature.

\section{WIDE BANDGAP MATERIALS}

Wide bandgap materials offer the advantage of lower leakage currents at elevated temperatures. Leakage current densities are about a factor of 20 less for GaAs, 1,000 less for AlGaAs, and about 10,000 less for GaP compared to silicon. The intrinsic threshold is also much higher due to the wider bandgaps. There are other advantages to using semiconductor materials other than silicon, and some of the major issues are described below. Bandgaps for a few of the more popular materials are listed in Table 1.

TABLE 1. Bandgap Energies for Selected Semiconductor Materials.

Material $\quad$ Bandgap (eV)

$\begin{array}{ll}\text { Silicon } & 1.12 \\ \text { GaAs } & 1.43 \\ \text { GaP } & 2.24 \\ \text { AlGaAs } & 1.43-2.15 \\ \text { AlGaP } & 2.24-2.45 \\ \text { B-SiC } & 2.3 \\ \text { 6H-SiC } & 2.9 \\ \text { Diamond } & 5.5\end{array}$

\section{GALLIUM ARSENIDE}

GaAs technology has established its marketability in high speed analog and digital integrated circuit applications and in optoelectronic applications. JFETs fabricated and tested by McDonnell Douglas have shown acceptable device performance to $445 \mathrm{~K}$. MESFETs fabricated by Honeywell have been tested to $670 \mathrm{~K}$. The FET on/off current ratio decreases from $10: 1$ at $295 \mathrm{~K}$ to $20: 1$ at $670 \mathrm{~K}$. Although the degradation is fatal for some applications, it can be handled for digital and small signal RF applications. Work continues to improve the device performance at high temperatures. GaAs operational amplifiers have been designed which have stable performance up to $570 \mathrm{~K}$ by the High Frequency Institute at the Technical University of Darmstadt. 


\section{GALLIUM PHOSPHIDE}

Gallium phosphide (GaP) is recognized as a good material for high-temperature operation. Sandia has successfully fabricated and tested bipolar junction transistors to $720 \mathrm{~K}$ and thyristors to $770 \mathrm{~K}$. However, industry is reluctant to use GaP materials due to potential contamination problems.

\section{HETEROJUNCTIONS}

Heterojunctions of AlGaAs and AlGaP offer several advantages over junctions using GAP or GaAs. The structures allow the bandgap to be tailored to reduce leakage currents, while providing a reasonably low forward voltage drop. The forward voltage drop would be limited to that of the GaAs or GaP junction. Heterostructures also allow the device processor to tailor the structure at the device metal contacts to enhance ohmic contacting. AlGaAs as bipolar junction transistors (BJTs) have been operated to $750 \mathrm{~K}$ and AlGaP BJTs and rectifiers (SCRs) have been operated to $820 \mathrm{~K}$.

\section{SILICON CARBIDE}

During the late 1960s, silicon carbide was considered to be the semiconductor material of the future. However, the growth processes were never fully understood, which ultimately ended commercial activity. During the past 6 years, research in material growth, doping, oxidation, and metallization has reached sufficient maturity to result in commercial sales of silicon carbide wafers and diodes. Cree Research has demonstrated the operation of FET devices to $920 \mathrm{~K}$. Commercialization of the $\mathrm{SiC}$ light-emitting diodes (blue LEDs) has been the driving force to this time, but another driver for $\mathrm{SiC}$ development is high-temperature and high-power semiconductors for microwave systems.

\section{DIAMOND}

Diamond research in the U.S. and abroad has been motivated by the promise of superio: mechanical and electrical properties. When compared to other semiconductors, Diamond's thermal conductivity of $20 \mathrm{~W} / \mathrm{cm} \mathrm{K}$ (even better than copper) makes it a preferred choice as a power device. The optical properties of diamond are unsurpassed for transmissivity and low absorption loss. The $5.5 \mathrm{eV}$ bandgap makes diamond useful for high temperatures, but oxidation problems limit the material to $1,270 \mathrm{~K}$. Other promising electrical properties include high electron and hole mobilities, high saturation velocity, and high breakdown voltage. At this time, research still continues in epitaxial growth, doping techniques, and metallization systems. Structural defects remain a problem and can be attributed to the growth process and substrate defects. At this time, only p-type doping has been demonstrated (boron). A permeable-base transistor (PBT) has been successfully fabricated and operated with a small gain to a temperature of $780 \mathrm{~K}$. Diamond is also receiving a great deal of attention for packaging applications. Its high thermal conductivity and excellent electrical insulating abilities (with high dielectric strength) make diamond an ideal substrate material for electronic circuitry since heat can be rapidly dissipated from the components while electrical isolation is maintained.

\section{VACUUM MICROELECTRONICS}

Developments in fabrication of microstructures have allowed solid-state versions of the vacuum tube to be developed. Two device types have been made which are radiation-hard and can operate at high temperatures.

\section{Thermionic Integrated Circuits (TICs)}

TIC development started in the late 1960s and was the result of the vacuum tube communities' attempt to compete with a rapidly growing semiconductor industry. The idea was to demonstrate integrated circuit capability by using conventional heated cathode techniques. A typical device used photolithographic and thin film deposition techniques in fabrication and measured about 25 microns square by $1 \mathrm{~mm}$ thick. Active devices were demonstrated to operate 
with a cathode temperature of $1,070 \mathrm{~K}$ (and package at $770 \mathrm{~K}$ ) for up to 1 year and accumulate $10^{17}$ neutrons/cm ${ }^{2}$ and $250 \mathrm{Mrad}(\mathrm{Si})$ gamma without degradation. The lack of cathode robustness limits the reliability of TICs as with all thermionic devices. Small oxygen ingress attacks and deteriorates the tungsten emitters. The other major drawback is the "cross talk" or device interactions that limit the ability to make a large-scale integrated circuit.

\section{Field Emitter Arrays (FEAs)}

FEAs are a collection of emitter tips in a package that provide an electron flow across a gap through field emission alone. The concept of field emission, without the need of thermionic agitation, was hypothesized in the 1920s, but emitter feature sizes were not possible until the 1970s when silicon IC feature sizes were reduced to below 10 microns. Emitter tips, or pyramids, are created using conventional IC processing to manufacture a micromachined part with a cathode (emitter), grids, and anode (collector). One commercial driving force behind FEA development is their utility as flat screen displays or TVs, but they should be very high-temperature and very radiation-hard. The current densities are $10^{7}$ to $10^{8} \mathrm{~A} / \mathrm{cm}^{2}$ which makes FEAs a candidate for power devices and the feature sizes make FEAs useful to ultra-high frequencies (transit times of less than $150 \times 10^{-15}$ seconds). Developments at the Naval Research Laboratory in 1986 have demonstrated the concept.

\section{CONCLUSIONS}

A large number of materials and device types have been demonstrated to work at high temperatures. In most cases, these devices have failed because of their metallization or packaging and not because of the semiconductor material. More research funding needs to be allocated toward understanding and testing high-temperature regimes of metallization and packaging of electronic materials. The development of reliable, high-temperature electronics will not only open new markets, but will also offer significant advantages in device reliability if these hightemperature parts are operated at lower temperatures $(<420 \mathrm{~K})$.

\section{Acknowledgments}

This work was supported by the Air Force Wright Aeropropulsion Laboratory under MIPR No. FY145-88-NO609 and performed at Sandia National Laboratories for the U.S. Department of Energy under contract number DE-ACO4$75 \mathrm{DP} 00789$.

\section{References}

Thome, F. V. and D. B. King, (1989) Final Report on Results of a Survey and Workshop and High-Temperature and Radiation-Hardened Electronics, SAND89-0975, Sandia National Laboratories, Albuquerque, NM.

Thome, F. V., D. B. King, and C. W. Severt, (1991-A) Final Report on Workshop on High-Temperature Electronics (Metallization and Packaging), SAND91-0370, Sandia National Laboratories, Albuquerque, NM.

King, D. B., F. V. Thome, and C. W. Severt, (1991-B) Transactions First International High-Temperature Electronics Conference, held in Albuquerque, NM, 16-20 June 1991.

King, D. B., F. V. Thome, and C. W. Severt, (1991-C) Proceedings First International High-Temperature Electronics Conference, held in Albuquerque, NM, 16-20 June 1991. 

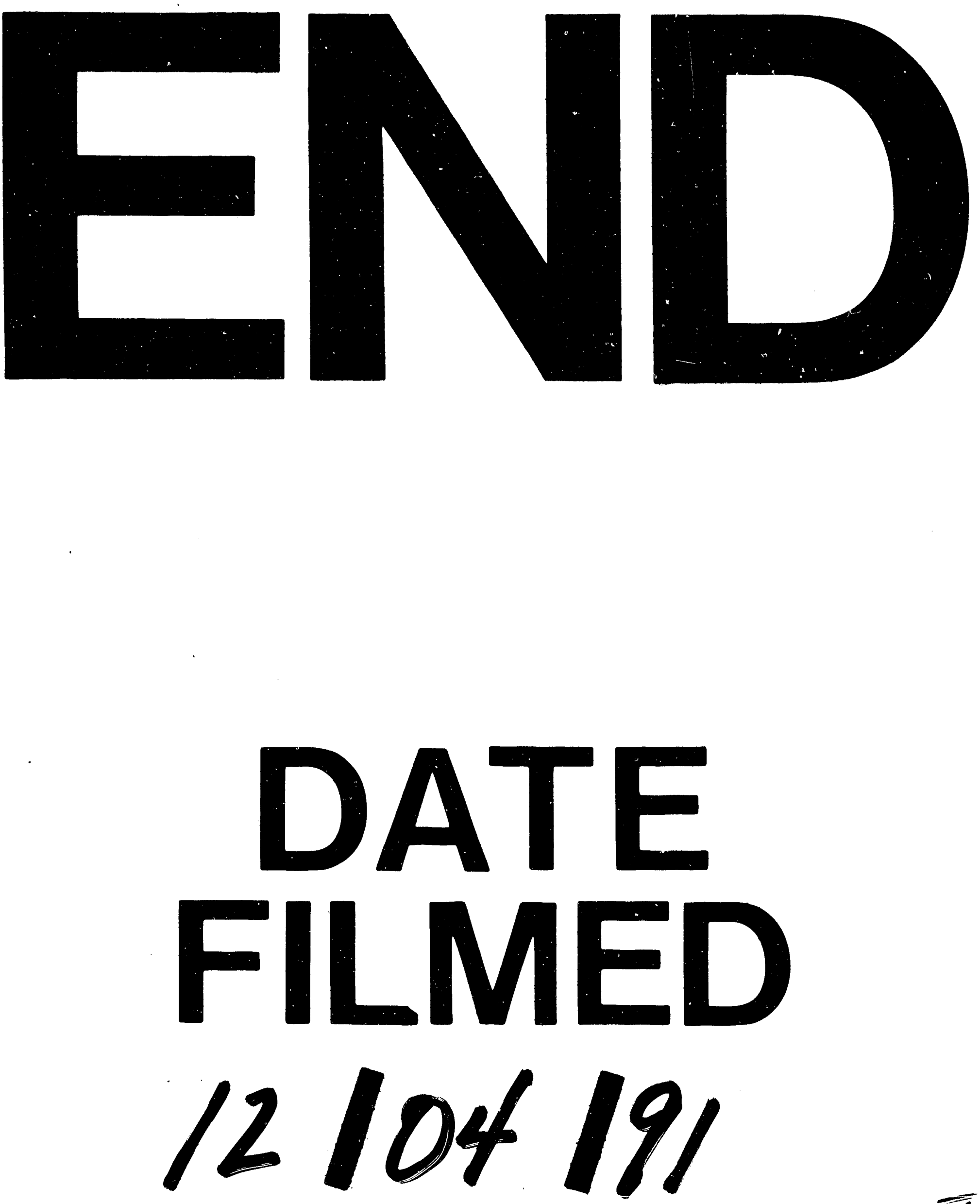

I 
